Pesq. Vet. Bras. 28(10):481-487, outubro 2008

\title{
Comparação genotípica de isolados de Corynebacterium pseudotuberculosis de caprinos e ovinos do sertão de Pernambuco ${ }^{1}$
}

\author{
Sílvio Romero de O. Abreu²*, Rinaldo A. Mota ${ }^{3}$, Grácia Maria S. Rosinha ${ }^{4}$, Odinéia \\ Forner $^{4}$, José W. Pinheiro Júnior ${ }^{3}$, Renata R.B. Pereira ${ }^{4}$, Roberto S. de Castro ${ }^{3}$, \\ Carina Elisei ${ }^{4}$, Cléber O. Soares ${ }^{4}$, Flábio R. Araújo ${ }^{4}$ e Renata C. Madureira ${ }^{4}$
}

\begin{abstract}
Abreu S.R.O., Mota R.A., Rosinha G.M.S., Forner O., Pinheiro Júnior J.W., Pereira R.R.B., Castro R.S., Elisei C., Soares C.S., Araújo F.R. \& Madureira R.C. 2008. [Genotypic comparison between Corynebacterium pseudotuberculosis samples obtained from sheep and goats with caseous lymphadenitis, raised in the semi-arid region of Pernambuco.] Comparação genotípica de isolados de Corynebacterium pseudotuberculosis de caprinos e ovinos do sertão de Pernambuco. Pesquisa Veterinária Brasileira 28(10):481-487. Clínica Escola de Medicina Veterinária, Faculdade de Ciências Biológicas e da Saúde, Centro de Ensino Superior de Maceió, Rodovia Divaldo Suruagy s/ n, Quadra 4, Lote 4, Praia do Francês, Marechal Deodoro, AL 57160-000, Brazil. E-mail: silviobiotec@yahoo.com.br

The objective was to genotypically compare 35 samples of Corynebacterium pseudotuberculosis obtained from abscesses of sheep and goats diagnosed with caseous lymphadenitis originated from 5 different municipalities in the semi-arid region of Pernambuco, Brazil. The RFLP-PCR technique with Hpy-Ch4 and Msp I and Pst I Msp I restriction enzimes was used to fingerprint the genes $r p o B$ and pld, respectively. The results demonstrate that there was no difference on the fragments banding pattern among samples, independently of the host species or geographic area studied, defining a homogeneous profile of $C$. pseudotuberculosis responsible for superficial abscesses for the region.
\end{abstract}

INDEX TERMS: Genotyping, RFLP-PCR, Corynebacterium pseudotuberculosis, goats, sheep.

RESUMO.- Objetivou-se com este estudo comparar genotipicamente 35 isolados de Corynebacterium pseudotuberculosis recuperados de conteúdo de abscessos de caprinos e ovinos com linfadenite caseosa, procedentes de cinco municípios localizados no Sertão de Pernambuco,

\footnotetext{
${ }^{1}$ Recebido em 31 de janeiro de 2008.

Aceito para publicação em 28 de maio de 2008.

2 Clínica Escola de Medicina Veterinária, Faculdade de Ciências Biológicas e da Saúde, Centro de Ensino Superior de Maceió (CESMAC), Rodovia Divaldo Suruagy s/n, Quadra 4, Lote 4, Praia do Francês, Marechal Deodoro, AL 57160-000, Brasil. *Autor para correspondência: silviobiotec@yahoo.com.br

${ }^{3}$ Departamento de Medicina Veterinária, Universidade Federal Rural de Pernambuco, Rua Dom Manuel s/n, Dois Irmãos, Recife, PE 52171900, Brasil.

${ }^{4}$ Centro Nacional de Pesquisa de Gado de Corte, Empresa Brasileira de Pesquisa Agropecuária, Rodov. BR 262 Km 4, Cx. Postal 154, Campo Grande, MS 79002-970, Brasil.
}

Brasil. Utilizou-se a técnica de fingerprint RFLP-PCR com as enzimas de restrição Hpy-Ch4 e Msp1 aplicada ao gene $r p o B$ e as enzimas Pst I e Msp I para o gene pld. Não houve diferença nos padrões de fragmentos de bandas entre os isolados, independente da espécie hospedeira ou da área geográfica estudada, definindo-se um padrão genotípico homogêneo de $C$. pseudotuberculosis responsável por abscessos superficiais na região.

TERMOS DE INDEXAÇÃO: Genotipagem, RFLP-PCR, Corynebacterium pseudotuberculosis, caprinos, ovinos.

\section{INTRODUÇÃO}

A linfadenite caseosa (LC) é uma doença infecto-contagiosa de pequenos ruminantes causada por Corynebacterium pseudotuberculosis e caracterizada clinicamente por abscessos caseosos que acometem os linfonodos, pele e vísceras (Unanian et al. 1985). Encontra-se amplamen- 
te distribuída no mundo e já foi relatada em vários Estados do Brasil, onde apresenta prevalência relativamente elevada no Nordeste brasileiro (Costa et al. 1973, Langenegger \& Langenegger 1991). De caráter insidioso e com tendência a cronicidade, é capaz de produzir perdas econômicas significativas para os criadores de pequenos ruminantes (Panton et al. 1988).

O gênero Corynebacterium está representado por mais de 60 espécies na sua maioria isolada de animais ou humanos (Khamis et al. 2005). A bactéria apresenta-se sob a forma de clava, sendo o Corynebacterium diftericum o protótipo do grupo. Entretanto, algumas corinebactérias são pleomórficas e formam elementos cocóides durante o seu crescimento (Birberstein \& Hirsh 2003).

Corynebacterium pseudotuberculosis é um difteróide típico, apresentando-se sob a forma cocóide a filamentosa, não possuem cápsula e sua parede celular é típica das corinebactérias com elevada concentração de lipídeos, que torna a torna hidrofóbica e pode contribuir para a sua sobrevivência dentro dos fagócitos e para sua leucotoxicidade (Birberstein \& Hirsh 2003).

Dentro da espécie C. pseudotuberculosis, são reconhecidos dois biovares que foram diferenciados inicialmente pela capacidade ou não em reduzir nitrato a nitrito. O biovar equi, nitrato-positivo, é normalmente isolado de eqüinos e bovinos, e biovar ovis, nitrato-negativo, é isolado, invariavelmente, de caprinos e ovinos, mas também de bovinos (Songer et al. 1988). Entretanto, já foi demonstrado que o biovar equi pode, apesar de pouco freqüente, apresentar-se sob a forma de nitrato-negativo, mantendo, no entanto, sua classificação anterior com base em estudo de ribotipagem (Costa et al. 1998).

A investigação taxonômica dos procariontes pode ser dividida em dois períodos: no primeiro, os estudos eram centrados nas características fenotípicas e, no segundo, o foco passou a ser as características genotípicas. Este último foi pautado na detecção de regiões altamente conservadas do genoma, de áreas que sofreram alguma variação como inserção, deleção ou mutação de nucleotídeos específicos para uma espécie ou mesmo amostra (Tortoli 2003).

A genotipagem baseia-se em técnicas de fácil reprodutibilidade, tendo um forte poder discriminatório. As várias técnicas disponíveis passaram a serem conhecidas como técnicas de "DNA fingerprinting" (Darine et al. 1998).

A técnica de RFLP (Polimorfismo de Comprimentos de Fragmentos de Restrição) é comumente empregada para a diferenciação entre indivíduos de uma mesma espécie, mas de cepas diferentes. Esta técnica pode ser realizada associada à $\mathrm{PCR}$, Reação em Cadeia da Polimerase (RFLP-PCR). Nesta, um determinado fragmento gênico é amplificado com primers específicos para o gene e, posteriormente, submetidos à ação de enzimas de restrição que cortam este gene, ou seu segmento, em pontos específicos, produzindo assim fragmentos de DNA (Darine et al. 1998, Sutherland et al. 1993).

O uso de métodos moleculares para análise seqüencial do gene RNAr 16S (DNAr) tem facilitado um maior delineamento do gênero, e a disponibilidade em comparar a seqüência deste gene com informações fenotípicas meIhoradas tem aumentado significativamente a confiabilidade na identificação das espécies. Estes avanços na taxonomia e métodos de detecção, junto com o interesse nas corinebactérias como agentes oportunistas em infecções em humanos, recentemente resultou no delineamento de um vasto grupo de novas espécies deste gênero (Khamis et al. 2005).

A grande maioria das espécies de Corynebacterium pode ser diferenciada pelo polimorfismo das bandas de restrição para o gene do RNAr 16 S devido à alta variabilidade das seqüências do DNAr $16 S$ interespécies para esse gênero, que pode ser visto por um grande número de padrões de restrição (Vaneechoutte et al. 1995).

Entretanto, este padrão de variabiliade interespécie não é verdadeiro para as espécies $C$. pseudotuberculosis e Corynebacterium ulcerans que não são diferenciadas entre si na sua filogenia quando comparadas suas seqüências do DNAr (Riegel et al. 1995).

Apesar do gene do RNAr 16S ser o marcador molecular mais utilizado para determinar as relações filogenéticas bacterianas, para o gênero Corynebacterium, o gene rpo $B$ (gene codificador da sub-unidade â da RNA polimerase) parece ser melhor marcador na distinção entre espécies desse gênero (Khamis et al. 2004).

Um dos fatores de maior relevância para a patogenia da linfadenite caseosa é a capacidade de C. pseudotuberculosis em produzir a exotoxina fosfolipase D (PLD) (Nairn et al. 1977, Hodgson et al. 1992; MacNamara et al. 1994). Esta toxina parece só ser produzida por duas espécies de Corynebacterium, C. pseudotuberculosis e $C$. ulcerans, sendo considerado um bom marcador para a identificação dessas duas espécies (Barksdale 1981).

Sutherland et al. (1989), compararam a PLD de quatro cepas de $C$. pseudotuberculosis frente à habilidade em matar ratos brancos, atividade hemolítica, capacidade em inibir a hemolisina estafilocóccica e a atividade antigênica para ELISA, encontrando variação na letalidade, mas não na antigenicidade. Esta variabilidade na intensidade da ação patogênica da PLD poderá ser resultado de mutações no gene pld (gene codificador da PLD).

Objetivou-se com este estudo analisar o perfil epidemiológico molecular de isolados de $C$. pseudotuberculosis, utilizando a técnica de RFLP-PCR, para os genes rpoB e pld de forma a contribuir com o conhecimento do comportamento do agente da linfadenite caseosa em rebanhos de caprinos e ovinos criados no sertão pernambucano.

\section{MATERIAL E MÉTODOS}

\section{Amostragem}

Pernambuco está localizado a $7^{\circ}$ e $15^{\prime}$ e $9^{\circ}$ e $27^{\prime}$ de latitude sul, e $34^{\circ}$ e $48^{\prime}$ e $41^{\circ}$ e $19^{\prime}$ de longitude oeste de Greenwich. Com área total de $98.526,60 \mathrm{~km}^{2}$, ocupa $6,3 \%$ do Nordeste brasileiro e 1,2\% do Brasil. O IBGE identificou em Pernambuco, 
em 1989, cinco Mesorregiões e 19 Microrregiões geográficas, a saber: Mesorregião do Sertão Pernambucano com 41 municípios; Mesorregião do São Francisco Pernambucano com 15 municípios, Mesorregião do Agreste Pernambucano com 71 municípios, Mesorregião da Mata Pernambucana com 42 municípios e Mesorregião Metropolitana do Recife com 15 municípios. Cada Mesorregião é dividida em Microrregiões, no total de 19. Assim, a Mesorregião do Sertão Pernambucano (região norte do Sertão), divide-se em: Microrregião de Araripina, Microrregião do Salgueiro, Microrregião do Pajeú e Microrregião do Sertão do Moxotó. A Mesorregião do São Francisco Pernambucano (região sul do Sertão), divide-se em: Microrregião de Petrolina e Microrregião de Itaparica (Andrade et al. 2003).

Foram selecionados cinco municípios para a coleta do material, estando três na Microrregião do Pajeú (Itapetim, São José do Egito e Carnaíba), um na Microrregião do Moxotó (Custódia) e um na Microrregião de Itaparica (Floresta). Por município foram visitadas, pelo menos, 25 propriedades, distribuídas de maneira a representar todo o espaço territorial.

Analisaram-se 35 amostras de conteúdo de abscessos superficiais, 26 de caprinos e 8 de ovinos, sendo assim distribuídas: Carnaíba (6 amsotras de caprinos e 2 de ovinos); Itapetim (4 amostras de caprinos e 4 de ovinos); São José do Egito (11 amostras de caprinos); Floresta (6 amostras de caprinos e 2 de ovinos); e Custódia (uma amostra de ovino) (Fig.1).

As amostras foram obtidas, após tricotomia local e antisepsia com álcool iodado a $10 \%$, por punção aspirativa de abscessos fechados com auxílio de seringa descartável e agulha $40 \times 12 \mathrm{~mm}$.

O material coletado foi cultivado em ágar base enriquecido com $10 \%$ de sangue desfibrinado de ovino, sendo as placas incubadas a $37^{\circ} \mathrm{C}$ em aerobiose durante 48 horas. Posteriormente, foram selecionadas as colônias que apresentaram características compatíveis com o gênero Corynebacterium (Carter \& Cole 1990). Essas colônias foram submetidas à técnica de coloração de Gram, repicadas para o caldo Brain Heart Infusion (BHI) para posterior identificação utilizando o APIcoryne (BioMerieux-França), confirmando bioquimicamente as amostras como isolados de Corynebacterium pseudotuberculosis nitrato negativas (biovar ovis).

\section{Extração do DNA}

No Laboratório de Biologia Molecular da área de Sanidade Animal do Centro Nacional para Pesquisa de Gado de Corte
(Embrapa Gado de Corte), foi realizada a extração do DNA genômico pelo método modificado de Zhang et al. (1994). Para este procedimento, as amostras foram cultivadas em tubos Falcon de $50 \mathrm{ml}$ (com $10 \mathrm{ml}$ de caldo LB). Esse material foi centrifugado por 10 minutos a $6.000 \mathrm{xg}$. O pellet foi ressuspenso uma vez com $1 \mathrm{ml}$ de tampão TE 10mM, pH 8,7 (0,19g de EDTA $10 \mathrm{mM}+0,07 \mathrm{~g}$ tris $\mathrm{HCl} 10 \mathrm{mM})$. A suspensão foi transferida para tubos de $2 \mathrm{ml}$ que foram centrifugados por 10 minutos a $9.900 \mathrm{x}$ g. Posteriormente, descartado o sobrenadante, o pellet foi ressuspenso em 800ul de tampão TE (pH 8,7), contendo 10,3\% de glicose e $10 \mathrm{mg} / \mathrm{ml}$ de lisozima, sendo então incubada por 12 horas a $37^{\circ} \mathrm{C}$. Posteriormente, cada tubo recebeu $100 u$ de SDS a $10 \%$ + 20 ul de $\mathrm{NaCl}$ a $5 \mathrm{M}$ e $13 \mathrm{ul}$ de proteinase $\mathrm{K}$ a $20 \%$; a solução foi homogeneizada levemente e incubada por 12 horas a $56^{\circ} \mathrm{C}$. Em seguida, adicionou-se $0,8 \mathrm{ml}$ de fenol e após agitação leve em mesa agitadora por 20 minutos, a suspensão foi centrifugada por 10 minutos a $9.900 \times$ g. O sobrenadante foi então transferido para outro tubo estéril de $2 \mathrm{ml}$ e adicionado aproximadamente o mesmo volume de uma solução de fenol:clorofórmio:álcool isoamílico (25:24:1). Após agitação leve por 20 minutos, procedeu-se nova centrifugação por mais 10 minutos a 9.900 x g. O sobrenadante foi, mais uma vez, transferido para outro tubo estéril onde se adicionou aproximadamente a mesma quantidade de clorofórmio:álcool isoamílico (24:1). Novamente a solução foi submetida à agitação leve por 20 minutos e centrifugada a 9.900 x g, por 10 minutos. O sobrenadante foi transferido para outro tubo onde adicionou-se $0,6 \%$ (do volume total do sobrenadante) de isopropanol para a precipitação do DNA. A suspensão foi homogeneizada levemente e centrifugada novamente a $9.900 \times$ g, por mais 10 minutos. Descartado o sobrenadante, adicionou-se $1 \mathrm{ml}$ de álcool a $70 \%$ para lavar o DNA e retirar as impurezas. Logo após centrifugou-se por 5 minutos a 9.900 x g; descartado o sobrenadante, deixouse o pellet secar a temperatura ambiente, sendo ressuspenso em $50 u l$ de água ultra-pura e estocado a $-20^{\circ} \mathrm{C}$.

\section{Amplificação dos genes}

A partir da seqüência depositada no Genbank (http:// www.ncbi.nlm.nih.gov/entrez), do gene pld sob o número de acesso L16587 e de acordo com Khamis et al. (2004) foram desenhados os primers para segmentos dos genes pld e rpoB, respectivamente. Os primers utilizados para o gene pld foram, F 5' ATGAGGGAGAAAGTTGTTTTA 3' e R 5' TCACCACGGGTTATCCGC 3'. Sendo a amplificação realizada em termociclador com o seguinte protocolo: etapa de 3 minutos a

$$
\text { São José do Egito }
$$

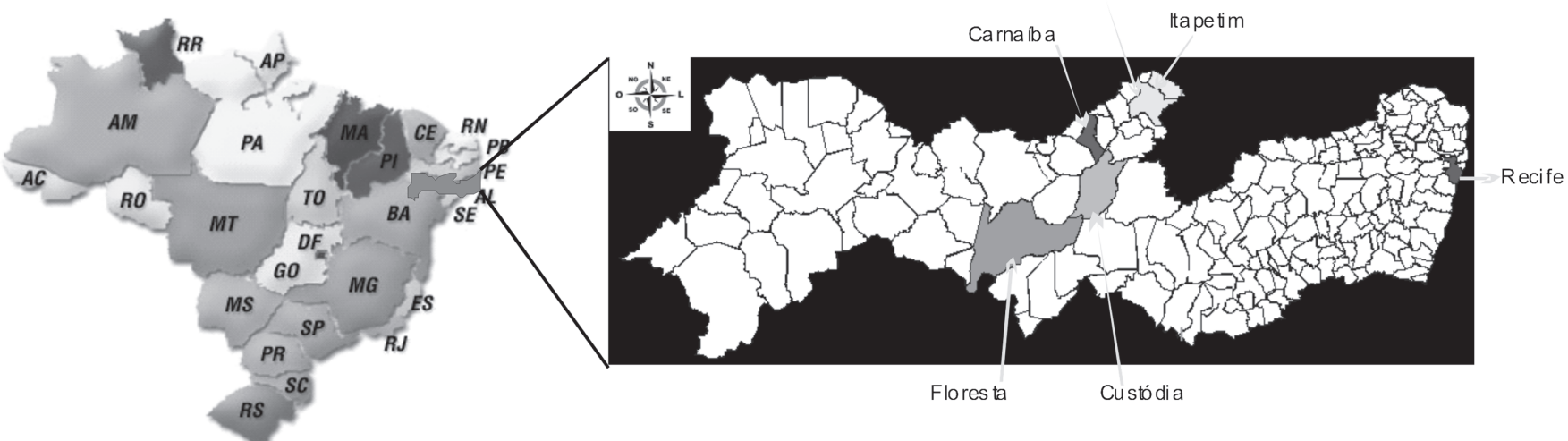

Fig.1. Mapa do Brasil com destaque para o Estado de Pernambuco e localização dos cinco municípios estudados para linfadenite caseosa em ovinos e caprinos, na macro-região do Sertão e a sua capital, Recife, Pernambuco, 2007. 


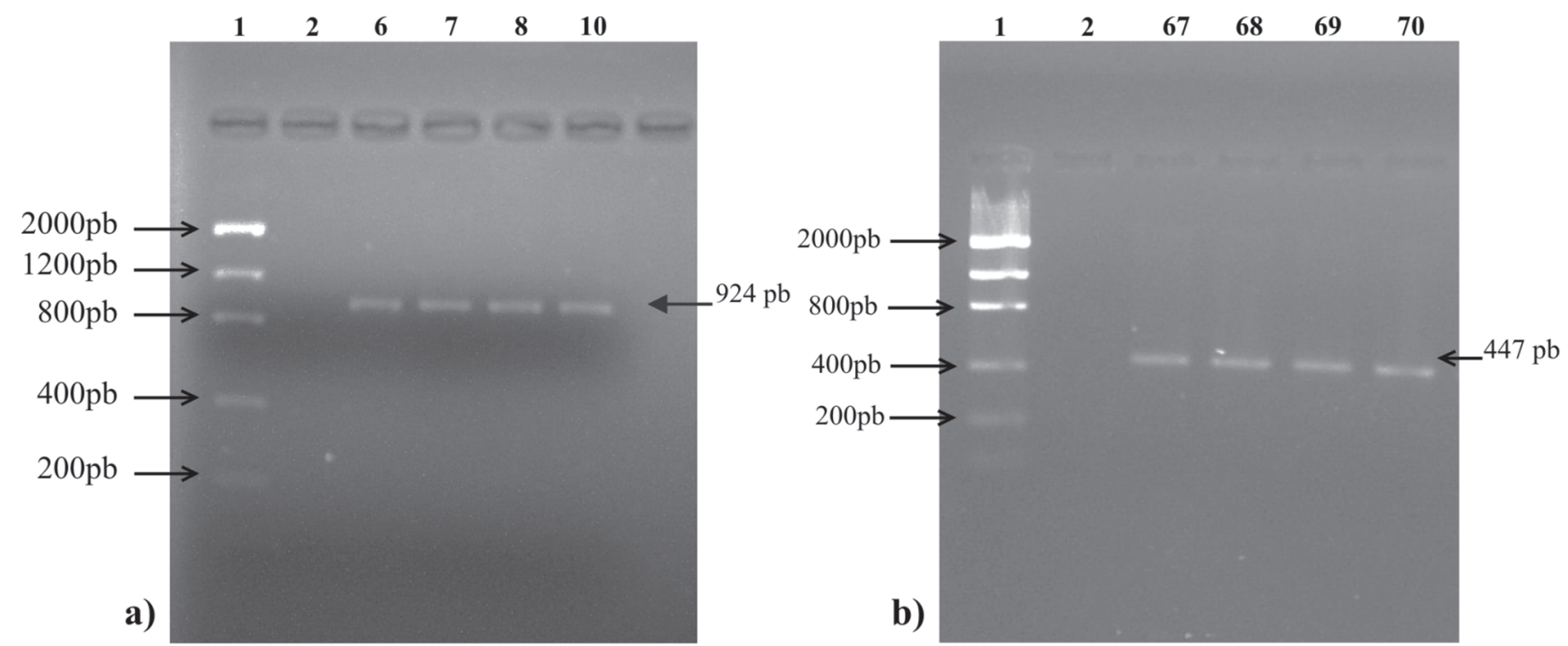

Fig.2. a) Perfil de bandas da reação de PCR utilizando primers do gene pld de Corynebacterium pseudotuberculosis. Marcador de pares de bases Low DNA Mass Lader (1), Controle Negativo (2), padrão do gene pld (Amostras 6, 7, 8 e 10). b) Perfil de bandas da reação de PCR utilizando primers do gene rpoB de Corynebacterium pseudotuberculosis. Marcador de pares de bases Low DNA Mass Lader (1), Controle Negativo (2), padrão do gene rpoB (Amostras 67, 68, 69 e 70). Eletroforese em gel de agarose a 2\%.

95ํㅡ, 35 ciclos de 1 minuto a 95ำ para a desnaturação, 1 minuto a $58^{\circ} \mathrm{C}$ para o anelamento, 2 minutos a $72^{\circ} \mathrm{C}$ para a extensão da cadeia e mais 3 minutos a $72^{\circ} \mathrm{C}$ para a extensão final, gerando bandas de $924 \mathrm{pb}$. Para o gene $r p o B$, as seqüências de primers utilizadas foram, $F$ ' CGTATGAACATCGGCCAG 3' e R 5' TCCATTTCGCCGAAGCGC 3', com amplificação em termociclador sob o seguinte protocolo: etapa de 3 minutos a 95ㅇ, 34 ciclos de 1 minuto a $95^{\circ} \mathrm{C}$ para a desnaturação, 45 segundos a $56^{\circ} \mathrm{C}$ para o anelamento, 1 minuto e 30 segundos a $72^{\circ} \mathrm{C}$ para a extensão da cadeia e mais 10 minutos a $72^{\circ} \mathrm{C}$ para a extensão final, gerando bandas de $447 \mathrm{pb}$. As reações de PCR foram realizadas em termociclador de gradiente (Eppendorf Mastercycler gradient), com um volume final de $50 \mu \mathrm{L}$ contendo $5 \mu \mathrm{L}$ de tampão de PCR 10X, 1,5mM de $\mathrm{MgCl}_{2}, 250 \mu \mathrm{M}$ de cada dNTP, 2,5 U de taq DNA polimerase (Invitrogen $囚$ ), $1 \mu \mathrm{L}$ de cada primer e $1 \mu \mathrm{L}$ de DNA molde.

Os produtos da amplificação foram observados por eletroforese a $100 \mathrm{~V}$ por 1 hora, separados por gel de agarose a $2 \%$, corados com brometo de etídio e visualizados com transluminador sob luz ultravioleta, utilizando como padrão o marcador Low mass (Invitrogen®) para quantificar o tamanho dos fragmentos (Fig.2).

\section{Digestão enzimática}

Para testar a melhor concentração enzimática, 500ng do produto de PCR de um isolado foi digerido com $1 \mu \mathrm{L}, 1,5 \mu \mathrm{L}$ e $2 \mu \mathrm{L}$ da enzima de restrição Pstl (Invitrogen $囚)$. Após o teste de concentração enzimática, foi utilizado como padrão $20 U$ das endonucleases Pstl e Mspl que possuem respectivamente os seguintes sítios de restrição para o gene pld: 5'CTGCA/ G 3', e 5' C /CGG 3'.

Para o gene rpoB foi utilizado $2 \mu \mathrm{L}$ (20U) das enzimas HpyCh4 (NewEngland®) e Mspl (Amersham®). As reações de digestão foram incubadas a $37^{\circ} \mathrm{C}$ por 6 horas e posteriormente submetidas à eletroforese em gel de poliacrilamida a $15 \%$ a $80 \mathrm{~V}$ por 3 horas, seguido de coloração em brometo de etídio
(5mg/mL) por 20 minutos. O marcador Low DNA Mass Ladder (Invitrogen $囚$ ) e um fragmento intacto do gene também foram aplicados aos géis como padrão para estimar o tamanho dos fragmentos gerados pela digestão.

\section{RESULTADOS E DISCUSSÃO}

A região Nordeste do Brasil é a que apresenta a maior freqüência de casos de linfadenite caseosa, provavelmente em decorrência da grande concentração de ovinos e caprinos, do tipo de vegetação que contém espinhos, facilitando a abertura de soluções de continuidade que servem como porta de entrada para as bactérias e do baixo grau de instrução dos criadores (Veschi 2005).

Situado nesta região, o Estado de Pernambuco tem o Sertão como sua maior região natural, ocupando $70 \%$ do seu território, com sua economia baseada na pecuária, principalmente bovina, caprina e ovina, sendo as duas últimas de grande importância econômica, principalmente para o pequeno produtor. Os municípios estudados situam-se nas microrregiões do Sertão do Pajeú e Sertão do Moxotó, predominando, em quase toda a área das duas regiões, o clima semi-árido e uma forte concentração de caprinos e ovinos (Pernambuco de A/Z 2007).

Somando-se os cinco municípios estudados, foram visitadas aproximadamente 100 propriedades, encontrando-se, em todas elas, animais que apresentavam abscessos superficiais ou animais com lesões de abscessos que haviam rompido naturalmente ou por intervenção do proprietário. Esses resultados indicam a grande circulação do agente e disseminação dos focos da doença no sertão pernambucano.

As culturas do conteúdo dos abscessos obtidos dos caprinos e ovinos estudados resultaram no crescimento de mais de um tipo de microrganismo, demonstrando a 
provável pluralidade de agentes infecciosos envolvidos nos processos abscedativos dos pequenos ruminantes. Dentre as bactérias, isoladas em associação a Corynebacterium pseudotuberculosis, destacaram-se Staphylococcus sp. e bactérias Gram-negativas não identificadas. Esses achados estão de acordo com Saïd et al. (2002) que também relataram o isolamento de Staphyloccocus aureus subsp. anaerobius, Streptoccocus sp. entre outros, de conteúdo de abscessos de ovinos na Tunísia. Quanto ao tempo de isolamento, observou-se crescimento de colônias consideradas características do gênero Corynebacterium sp. (pequenas colônias esbranquiçadas, mucosas e que, ao serem pinçadas, tendem a se deslocar por completo) em 48 horas de incubação como relatado por Connor et al. (2000). Em poucos casos, observou-se crescimento sem a formação de verdadeiras colônias, mas sim como pequenos agrupamentos puntiformes disseminados no agar.

No meio de cultura líquido (caldo $\mathrm{BHI}$ ), observou-se o turvamento deste com a presença de uma membrana, provavelmente em função da grande quantidade de lipídios da célula bacteriana que é uma característica peculiar desse agente, concordando com as observações feitas por Batey (1986).

Observaram-se bactérias Gram-positivas, na sua grande maioria cocóides com a presença de alguns cocobacilos. Apesar de muitos autores relatarem que o grupo Corynebacteria se apresenta como bastões, desenhando formas em paliçada ou letras chinesas, Biberstein \& Hirsh (2003), afirmaram ser esta espécie pleomórfica, apresentando-se muitas vezes na forma cocóide ou de cocobacilos.

Apenas os isolados identificados com 99 a $100 \%$ de certeza pelo teste APIcoryne (BioMeriuex-França) como pertencentes à espécie C. pseudotuberculosis biovar ovis tiveram o seu DNA extraído e sua identidade confirmada por PCR.
A análise de restrição revelou que a enzima $\mathrm{Hpv}$ - $\mathrm{Ch} 4$ cortou o gene rpoB em dois pontos, gerando bandas de 86, 126 e 235 pares de base (pb) e a Msp I realizou o corte em três locais, gerando quatro bandas com 54,78 , 93 e 222 pb (Fig.3).

O gene pld foi cortado em três pontos pela Pst I, produzindo fragmentos de 52, 108, 369 e $395 \mathrm{pb}$, enquanto que a Msp I gerou bandas de 72, 91, 195 e 566 pb (Fig.4).

Este trabalho comparou por RFLP-PCR o gene pld que codifica para o principal fator de virulência, a esfingomielinase, fosfolipase $\mathrm{D}$. Os resultados demonstram que entre os isolados de C. pseudotuberculosis biovar ovis aqui estudados, independente da região de origem ou da espécie hospedeira de onde foram obtidos, não houve variação genotípica para esse gene. Este fato sugere que este fator de virulência contra o qual muitos trabalhos de proteção vacinal têm sido elaborados (Ellis et al. 1991, Tachedjian et al. 1995, Hodgson et al. 1999), mantém uma homogeneidade nas suas características genéticas, permitindo assim que a resposta imune desenvolvida contra a PLD possa ser explorada como instrumento de controle da doença também na região estudada.

Vários trabalhos de ribotipagem foram desenvolvidos até o momento buscando comparar padrões genotípicos entre amostras de $C$. pseudotuberculosis utilizando o gene 16S, tendo todos eles encontrado homogeneidade das amostras dentro dos seus respectivos biovares, mesmo entre aquelas com origem em mais de uma região do mundo e causando nos hospedeiros sintomas de intensidade variável (Sutherland et al. 1993, 1996, Costa et al. 1998, Literák et al. 1999).

O gene $r p o B$ que codifica a sub-unidade â da RNA polimerase, responsável por toda a transcrição do DNA em RNA, tem sido revelado como um excelente marcador molecular para estudar as variações genotípicas entre espécies, mostrando-se, especificamente para Coryne-
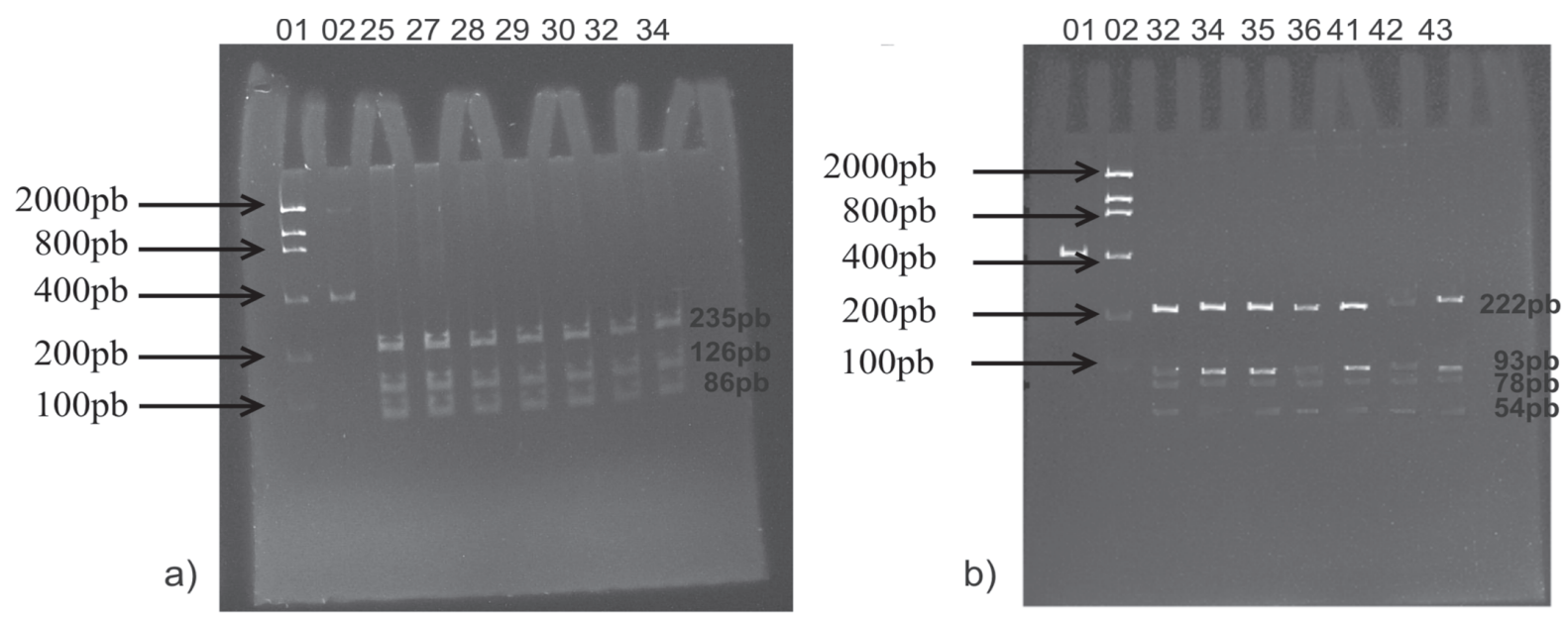

Fig.3. Perfis de restrição do gene $r p o B$ digeridos com $\mathrm{Hpy}-\mathrm{CH} 4$ por PCR em gel de poliacrilamida a 15\%. a) Gel, marcador Low DNA Mass Ladder (1), PCR não digerida (2), Amostras de Corynebacterium pseudotuberculosis $(25,27,28,29,30,32$ e 34). b) No gel, produto de PCR do gene rpoB não digerido (1), marcador Low DNA Mass Ladder (2), produtos de PCR digeridos com Msp I (Amostras 32, 34, 35, 36, 41, 42 e 43). 

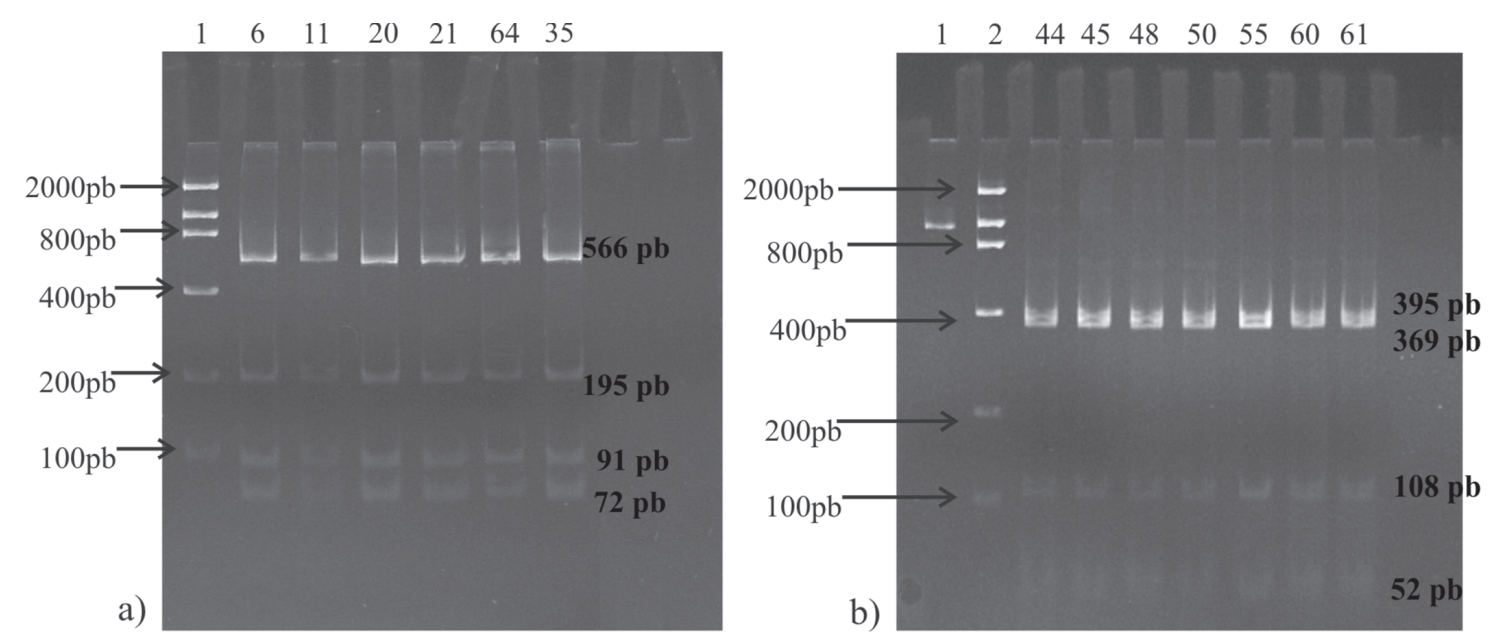

Fig.4. Perfis de restrição do gene pld $(924 \mathrm{pb})$ digeridos com Pstl por PCR em gel de poliacrilamida a $15 \%$. a) Gel, marcador Low DNA Mass Ladder (1), Amostras de Corynebacterium pseudotuberculosis (6, 11, 20, 21, 64 e 35). b) No gel, produto de PCR do gene pld não digerido (1), marcador Low DNA Mass Ladder (2), produtos de PCR digeridos com Mspl, (Amostras 44, 45, 48, 50, 55, 60 e 61).

bacterium pseudotuberculosis, um alvo ainda mais valioso do que o estudo comparativo do gene 16S (Khamis et al. 2004).

Também para o gene rpoB não foi observado polimorfismo nas bandas de restrição com as enzimas $\mathrm{Hpv}$ Ch4 e Msp I dentre as amostras aqui estudadas. Este resultado reforça a idéia de uma homogeneidade e estabilidade genética dentre a espécie Corynebacterium pseudotuberculosis, biovar ovis, nesta região. Como as amostras foram selecionadas frente a características morfológicas e bioquímicas que indicavam com praticamente $100 \%$ de certeza tratar-se de C. pseudotuberculosis, o reconhecimento de um padrão genético estável de um gene de baixo grau de mutação e imprescindível para a sobrevivência desta espécie, aliado a um comprovado alto poder discriminatório entre espécies, nos permite colocar está técnica como possível ferramenta diagnóstica para a LC.

Os resultados indicam que a $\mathrm{LC}$ em caprinos e ovinos do Sertão pernambucano é causada por C. pseudotuberculosis, biovar ovis, que não sofreu mutações detectáveis no seu gene de virulência de maior importância.

O conhecimento mais detalhado desses padrões de fragmentos através de estudos de seqüênciamento poderiam confirmar estes resultados.

\section{CONCLUSÕES}

A comparação dos padrões de banda por RFLP-PCR para os genes $r p o B$ e pld demonstram que as amostras estudas não apresentam qualquer variação genotípica frente às três enzimas de restrição. Os padrões homogêneos das bandas geradas para ambos os genes, pld e $r p o B$, independente da espécie hospedeira de pequeno ruminante ou da área geográfica estudada, reforça a idéia de um padrão genotípico único do Corynebacterium pseudotuberculosis biovar ovis.
A homogeneidade nos padrões de bandas para os genes $r p o B$ e pld oferece um meio eficiente de identificação de isolados de C. pseudotuberculosis permitindo que estes possam ser utilizados em métodos de diagnóstico.

Entretanto, novos estudos deverão ser conduzidos para que se conheça a seqüência nucleotídica desses fragmentos, proporcionando visão mais acurada da característica genotípica dessas amostras para os genes aqui estudados. A confirmação da condição de homogeneidade para o gene pld para C. pseudotuberculosis deverá incentivar um aumento no número de pesquisas voltadas para o desenvolvimento de vacinas mais eficazes e seguras.

\section{REFERÊNCIAS}

Andrade M.C.O., Sampaio F.A.C., Neto J.C.X.A., Jatobá L., Albuquerque M.J.C., Benjamin R.C., Andrade T.L.C. \& Lins F.J.C.C. 2003. Atlas Escolar Pernambuco: espaço geo-histórico e cultural. $2^{\mathrm{a}}$ ed. Editora Grafset, João Pessoa.

Barksdale L., Linder R., Sulea I.T. \& Pollice M. 1981. Phospholipase D activity of Corynebacterium pseudotuberculosis (Coynebacterium ovis) and Corynebacterium ulcerans, a distinctive marker within the genus Corynebacterium. J. Clin. Microbiol. 13(2):335-343.

Batey R.G. 1986. Factors affecting the yield of viable cells of Corynebacterium pseudotuberculosis in a liquid medium. Vet. Microbiol. 11(1/ 2): $145-152$

Biberstein E.L. \& Hirsh D.C. 2003. Corynebactérias; Arcanobacterium (Actinomyces) pyogenes; Rhodococcus equi, p.119-126. In: Hirsh D.C. \& Zee Y.C. (Ed.), Microbiologia Veterinária. $2^{\mathrm{a}}$ ed. Editora Guanabara Koogan, Rio de Janeiro.

Brasil. Ministério da Agricultura, Pecuária e Abastecimento. Acesso em 6 de janeiro de 2007. http://www.abrasil.gov.br/ avalppa/ RelAvalPPA2002/content/av_prog/072/prog072.htm

Brasil. Ministério do Planejamento. Acesso em 6 de janeiro de 2007. http://www.abrasil.gov.br/avalppa/site/content/ av_prog/05/15/ prog0515.htm

Carter G.R. \& Cole Jr J.R. 1990. Diagnostic Procedure in Veterinary Bacteriology and Mycology. 5 ${ }^{\mathrm{a}}$ ed., Academic Press. 620p.

Connor K.M., Quirie M.M., Baird G. \& Donachie W. 2000. Characterization of United Kingdom Isolates of Corynebacterium 
pseudotuberculosis using pulsed-field gel electrophoresis. J. Clin. Microbiol. 38 (7):2633-2637.

Costa M.D.M., Câmara J.Q., Rocha J.V.N. \& Martinez T.C.N. 1973. Linfadenite caseosa dos caprinos no Estado da Bahia. Distribuição geográfica da doença. Bolm Inst. Biol. Bahia, Salvador, 12(1):1-7.

Costa L.R.R., Spier S.J. \& Hirsh D.C. 1998. Comparative molecular characterization of Corynebacterium pseudotuberculosis of different origin. Vet. Microbiol. 62:135-143.

Darine A.L.C., Magalhães V.D. \& Crott L.S.P. 1998. Aplicações da ribotipagem na epidemiologia molecular de infecções bacterianas: revisão. Medicina 30:73-80.

Ellis J.A., Hawk D.A., Mills K.W.\& Pratt D.L. 1991. Antigen specificity and activity of ovine antibodies induced by immunization with Corynebacterium pseudotuberculosis culture filtrate. Vet. Immunol. Immunopathol. 28(3-4):303-316.

Hodgson A.L., Krywult J., Corner L.A., Rothel J.S. \& Radford A.J. 1992. Rational attenuation of Corynebacterium pseudotuberculosis: potential cheesy gland vaccine and live delivery vehicle. Infect. Immun. 60:29002905.

Hodgson A.L.M., Carter K., Tachedjian M., Krywult J., Corner L.A., McColl M. \& Camaron A. 1999. Efficacy of an ovine caseous lymphadenitis vaccine formulated using a genetically inactive form of the Corynebacterium pseudotuberculosis phospholipase D. Vaccine 17:802-808.

Khamis A., Raoult D. \& La Scola B. 2004. rpoB gene sequencing for identification of Corynebacterium species. J. Clin. Microbiol. 42 (9): 3925-2931.

Khamis A., Raoult D. \& La Scola B. 2005. Comparison between rpoB and $16 S$ rRNA gene sequencing for molecular identification of 168 clinical isolates of Corynebacterium. J. Clin. Microbiol. 43(4):19341936.

Langenegger C.H. \& Langenegger J. 1991. Monitoramento sorológico e alérgico da infecção por Corynebacterium pseudotuberculosis em caprinos. Pesq. Vet. Bras. 11(1/2):31-34.

Literák I., Horváthova A., Jahnová M., Rychlík I. \& Skalka B. 1999. Phenotype and genotype characteristics of Slovak and Czech Corynebacterium pseudotuberculosis strains isolated from sheep and goats. Small Rumin. Res. 32:107-109.

Nairn M.E., Robertson J.P. \& McQuade C.C. 1977. The control of caseous lymphadenitis in sheep by vaccination. Proc. $54^{\text {th }}$ Annu. Conf. Australian Vet. Assoc. 54:159-161.

McNamara P.J., Bradley G.A. \& Songer J.G. 1994. Targeted mutagenesis of the phospholipase $D$ gene results in decreased virulence of Corynebacterium pseudotuberculosis. Mol. Microbiol. 12:921-930.

Panton M.W., Mercy A.R., Wilkinson F.C., Gardner J.J., Sutherland S.S. \& Ellis T.M. 1988. The effects of caseous lymphadenitis on wool production and bodyweight in young sheep. Aust. Vet. J. 65(4):117119.

Pernambuco de A/Z. Disponível em: <http://www.pe-az.com.br/regioes/ regioes.htm>. Acessado em: 05/01/2007.

Riegel P., Ruimy R., de Briel D., Prévost G., Jehl F., Christen R. \& Monteil H. 1995. Taxonomy of Corynebacterium diphthteriae and related taxa, with recognition of Corynebacterium ulcerans sp. nov. nom. rev., FEMS Microbiol. Lett. 126:271-276.

Saïd M.S.B., Maitigue H.B., Benzarti M., Messadi L., Rejeb A. \& Amara A. 2002. Contribution a l'etude epidemiologique et clinique de la lymphadenite caseuse chez lês ovins. Arch. Inst. Pasteur Tunis 79:51-57.

Songer J.G., Beckenbach K., Marshall M.M., Olson G.B. \& Kelley L. 1988. Biochemical and genetic characterization of Coryneacterium pseudotuberculosis. Am. J. Vet. Res. 49:223-226.

Sutherland S.S., Hart R.A. \& Buller N.B. 1993. Ribotype analysis of Corynebacterium pseudotuberculosis isolates from sheep and goats. Aust. Vet. J. 70(12):454-456.

Sutherland S.S., Hart R.A. \& Buller N.B. 1996. Genetic differences between nitrate-negative and nitrate-posite $C$. pseudotuberculosis strains using restriction fragment length polymorphisms. Vet. Microbiol. 49:1-9.

Tachedjian M., Krywult J., Moore R.J. \& Hodgson L.M. 1995. Caseous lymphadenitis vaccine development: site-specific inactivation of the Corynebacterium pseudotuberculosis phospholipase D gene. Vaccine 13(18):1785-1792.

Tortoli E. 2003. Impact of genotypic studies on mycobacterial taxonomy: the new mycobacteria of the 1990s. Clin. Microbiol. Rev. 16(2):319354.

Unanian M.D., Silva A.E.D.F. \& Pant K.P. 1985. Abscesses and caseous lymphadenitis in goats in tropical semi-arid North-East Brasil. Trop. Anim. HIth Prod. 17:57-62.

Vaneechoutte M., Riegel P., de Briel D., Monteil H., Verschraegen G., De Rouck A. \& Claeys G. 1995. Evaluation of the applicability of amplified r-DNA-restriction analysis (ARDRA) to identification of species of the genus Corynebacterium. Res. Microbiol. 146:633-641.

Veschi J.L. 2005. Linfadenite caseosa. VIII Encontro de Caprinocultores do Sul de Minas Gerais e Média Mogiana. Disponível em: <http:// www.capritec.com.br/pdf/linfadenite_caseosa.pdf> Acessado em: 15/ 01/2007.

Wilson K. 1994. Preparation of genomic DNA from bacteria. In: Ausubel F.A., Brent R., Kingston R.E., Moore D.D., Seidman J.G., Smith J.A. \& Struhl K. (Ed.), Current Protocols in Molecular Biology, Wiley, New York, unit 2.4:1-5.

Zhang Y., Praszkier J., Hodgson A. \& Pittard A.J. 1994. Molecular analysis and characterization of a broad-host-range plasmid, pEP2. J. Bacteriol. 179(18):5718-5728. 